\title{
FROM HACKATHON TO STUDENT ENTERPRISE: AN EVALUATION OF CREATING SUCCESSFUL AND SUSTAINABLE STUDENT ENTREPRENEURIAL ACTIVITY INITIATED BY A UNIVERSITY HACKATHON
}

\author{
David Cobham ${ }^{1}$, Carl Gowen², Bruce Hargrave ${ }^{1}$, Kevin Jacques $^{1}$, Jack Laurel ${ }^{2}$, \\ Scott Ringham ${ }^{2}$ \\ University of Lincoln, UK: academic member of staff \\ ¿University of Lincoln, UK: undergraduate student
}

Keywords: Hackathon, entrepreneur, student enterprise, and university-led business.

\begin{abstract}
Hackathons are a worldwide phenomenon, with both industry and educators considering the opportunities and benefits that they generate. They can provide a forum for innovation, networking, and product design and development, thereby offering multiple outcomes. This paper develops the authors' previous work on the effectiveness of utilising a hackathon as the spark for initiating student entrepreneurial activity by considering the success of the student enterprise that was created as a result and the extent to which that success was attributable to the hackathon event. Using a case study approach, the paper seeks to evaluate the effectiveness of using hackathon-type events to initiate a successful University student enterprise project and to identify the key elements in the future organisation of such a hackathon event that might lead to a sustainable and effective student enterprise. The paper outlines the findings from this project, which focus on the team building and bonding that take place in such an event, and concludes with a series of recommendations from the authors on how one should market and structure a hackathon to best ensure the success of a subsequently formed student enterprise, based on the evaluation of the project one year after it was founded.

The evaluation of the project was undertaken as part of the institution's "Student as Producer" initiative where students and staff work side-by-side on research projects. An independent team of undergraduate students was fully involved in all aspects of the project evaluation, including the authoring of this paper.
\end{abstract}

Keywords: Entrepreneur, student enterprise, hackathon.

\section{INTRODUCTION}

This paper develops the authors' previous work on the effectiveness of utilising a hackathon as the spark for creating student entrepreneurial activity. That paper [1] looked at the earlier stages of the project; in particular, it focused on the key factors in the organisation of such a hackathon event that might ensure the success of that event. The paper outlined the findings from that project, and concluded with a series of recommendations as to how such a hackathon event might best be managed to ensure its success. The key success factors identified were:

- $\quad$ an extended timescale (a 48-hour event spread over three days was considered optimal);

- provision of a team of organisers to supervise the event;

- a creative rather than competitive environment;

- participation by students from a broad range of academic disciplines;

- a combination of allowing friendship groups with some management of group membership to ensure mixed skill-sets;

- realistic goals with a focus on design requirements and prototypes over finished coded solutions. 
The student enterprise project initiated by the hackathon has now been underway for over a year. In this paper the authors revisit the project to evaluate its success and to see the extent to which it has been influenced by its origin in the hackathon activity.

In order to encourage graduate employability, a number of universities have initiated projects promoting entrepreneurial activity amongst their student body [2] [3] [4]. An example of this is in the formation of University student enterprises [2] [5]. These internally-hosted businesses, operated by the students themselves with occasional support from staff, allow the students to experience entrepreneurial activity in an environment that is relatively low in risk and where the cost of failure is low. A three-day hackathon event, 'AppFest', was held at the University of Lincoln with the intention of bringing together teams of students that would potentially form themselves into a number of student enterprises. As a result of participating in the hackathon, it was intended that groups of students would take forward the positive experiences of working creatively and collaboratively together and, with assistance from the University, create new start-up businesses. It was expected that the nature of the companies created would focus on app development.

\section{LITERATURE REVIEW}

\section{Student Entrepreneurship}

While there is no agreed academic definition of an entrepreneur, there are a number of shared viewpoints. Bruyat and Julien [6] describe the vital importance placed on individuals who are entrepreneurs as producers of value for economies, along with the understanding that the individual has their own volition and doesn't simply respond to trends and environments. They describe how resources present in their environment can stimulate the development of potential entrepreneurs. Furthermore, Bruyat and Julien add that, for them, "the entrepreneur is the individual responsible for the process of creating new value".

Marchand, Hermens and Sood [7], partly inspired by the views Bruyat and Julien, define the student entrepreneur as "an individual attending award classes at university and conducting innovative and revenue generating entrepreneurial activities", though concede that in many cases in academia, the general understanding of a student entrepreneur is simply a student enrolled in an entrepreneurship course.

Entrepreneurs are perceived as critical to the development of new ventures, and entrepreneurship courses have appeared in Universities worldwide [8]; such courses can give students practical experiences from which to learn, to supplement and enrich the theoretical content [9]. A desire for increased entrepreneurial content in higher education is partly driven by difficulties in graduates finding employment, - irrespective of their qualifications gained [10]. It has been pointed out that graduate careers are also likely to contain periods of unemployment and self-employment, as well as more traditional hierarchical employment [11].

Research has indicated that having a family member involved in business or entrepreneurial activity has a positive effect (albeit often small) on young people's inclination towards entrepreneurship [12] [13] [14]. This aligns with other research on the effects of role models on students [15] [16] [17] [18]. Some research also indicated males engage more with entrepreneurship than females [5] [10] [14], however in a study of Malaysian students [12] it was found that gender had no effect on entrepreneurial intention.

In another study [10] it was further shown that "males rated their abilities better for topics that aligned strongly with entrepreneurship", while females were "more confident in areas that were not as exclusive to entrepreneurship", such as advertising and promotion - which they suggest is a product of social constructs. In the same study, they also found that students with entrepreneurs as parents rated their own abilities higher than those without. However, they note that while the "differences were statistically significant, effect sizes were fairly small".

Studies into entrepreneurship often focus on start-up businesses. The term 'start-up' is often used as a catch all term for young technology-related businesses [19]. Giardino et al. compared common themes in start-up related research, and consequently defined a start-up as "a small company exploring new business opportunities, working to solve a problem where the solution is not well-known and the market 
is highly volatile" [20]. They concluded that start-ups need to be agile and fast during development, recommending prototyping as essential; that start-ups need to adapt to customer wants and requirements in order to combat market uncertainty; and finally, since start-ups lack the resources of large corporations, their employees need to learn quickly from missteps and adapt to fill roles that emerge as the project grows.

\section{Enterprise in higher education}

A university's role in presenting an entrepreneurial curriculum can significantly influence students' inclination to an entrepreneurial career [12]. Universities also often continue to be involved with student enterprise even after graduation; Politis, Winborg and Dahlstrand refer to "a growing number of student entrepreneurs who are educated and nurtured in and around the context of the university and who after graduation continue to develop their new firms in close interaction with this highly knowledge-intensive milieu" [21].

A study carried out at Michigan Technological University [22] showed that the initial start-up planning and direction heavily determines the success of a project. In their student enterprise endeavours, an "advisor" is assigned to an enterprise group to provide support throughout. The advisor tends to be a member of existing university staff, however the advisor is there to serve as a coach or counsellor to the group and not to take away from any form of leadership role within the group. The study concluded that in real world entrepreneurship, the entrepreneur often has knowledge and motivation to take the risks required for business start-up. However, where the University is providing support, or where the concept has already been established through partnerships with the University, or the funding had already been committed, this can heavily reduce the risks of first time business start-up on the individuals. One aspect of this was to recruit students who were more senior to help to initiate the project before introducing earlier year students. The senior students could then also help support the lower level students until they felt comfortable.

Lancaster University also trialled a student enterprise and entrepreneurship scheme and have since listed benefits from undertaking the programme [23]. It was claimed that the University benefitted from the programme, for example in experiencing an increase in graduate employment, an increase in student satisfaction as well as building a better university reputation for the participants who might in turn become future employers. Increases in self efficacy, employability and in self-employment were all noted.

Similar benefits are also reflected in the findings of Burniston et al. [24], who identified a greater emphasis on employability skills, an improvement of grades (within the context of general increase in numbers graduating), and a greater preparedness for employability.

\section{THE EVENT}

The AppFest hackathon at the University of Lincoln, spread over three-days, took as its development focus a University Open Day companion app. The hackathon focused on the design and prototyping of the app; the intention was for the development and implementation of the app to take place after the conclusion of the event with one or more teams formed from those who attended.

As a closing item at the hackathon, the participating students were informed of the possibility to turn their creativity into reality and actually begin working on the open day application. This was introduced as a form of business start-up where the students could assume active roles within the business, whilst receiving university support through academic and technical mentors, and access to the University's central student enterprise support team. Around 10 students expressed an interest in continuing and then began to work on the product. This was perceived very well amongst those involved as it allowed them to be part of an entrepreneurial business as well as working on a real-world product, thus potentially improving their employability and enhancing their CVs. The result of the project was the official University of Lincoln Open Day Application, which allowed potential applicants to navigate the university campus, as well as giving them important information about the events taking place on the day and key information about the University. Once trialled in Beta form, the application was well received by visitors to the Open Day. Subsequently the team took on a number of commissions of App development work, some internally sponsored but others being commissioned by external clients. Working with the University's student enterprise support team the team was restructured and a number of management positions were created and recruited to, in order to give the enterprise a more robust 
operating structure. Students across year groups were involved at the outset, meaning that as students graduate and leave there is continuity of operation with students from earlier years stepping up to replace them and new students being recruited.

\section{METHODOLOGY}

A case study approach was chosen to conduct research into the success of the project. A set of criteria were drawn up to evaluate the degree of success of the approach adopted, and to provide a framework for making suggestions for similar future projects.

To support and further validate this approach, interviews and survey questionnaires [25] [26] were conducted. Both methods were used for gathering data from the students involved in the AppFest hackathon, and from university staff involved in running and organising both the hackathon and the subsequent enterprise extension project. The data gathered includes both quantitative and qualitative results which were combined with secondary research to attempt to evaluate the effectiveness of the project.

\section{ANALYSIS}

\section{University Enterprise Staff}

The central University Enterprise Support Team was involved from initial development of the concept of this project; however, as the intention of producing a start-up company was hidden to participants, they were not involved with participants during the event, and their contribution was focused on the project from the end of the AppFest. They stated that this was a probably a mistake, as making the purpose of the hackathon clear could have provided motivation and increased attendance for the event and allowed them to become involved earlier.

There were five student groups involved in the hackathon, the initial plan was to choose a winning group and develop their project. However, as good, creative aspects emerged from all five of the group it was decided instead to recruit to the student enterprise from all participating groups, resulting in 11 participants initially coming forward to work on the open day app project. With hindsight, the Enterprise Support Team felt that the group size created was too big. They concluded therefore that future attempts to launch an enterprise from a hackathon event, should be more competitive with the outcome taking only one group forward, instead of recruiting from all groups.

For the University Enterprise Support Team the AppFest was their first experience with a hackathon event. They believed that greater subject diversity in the student groups could benefit the project. They felt that pitching the hackathon more overtly as a launch pad for enterprise and crafting a product from the outset, could entice more students from Design and Business subjects to get involved. They noted the clear benefits of business students becoming involved at this stage as they would provide expertise that would be greatly beneficial in improving commercial awareness. However, they conceded that hackathons have an established atmosphere and ethos, which may be off-putting to students from disciplines other than the traditional ones such as computer science.

For future developments they believe, firstly, that client expectations should be laid out solidly, as team members lost a lot of time trying to meet ever changing expectations. Although this is a valuable realworld skill to master it was felt that this was one example where the safety of the University setting could have been exploited and such problems could have been mitigated.

The issue of payment for work undertaken was also cited as a concern by the Enterprise Support Team. It was felt that students should be paid on an hourly basis in order to remunerate the team members fairly.

They confirmed that functionality should be the foundation of the project, as opposed to a focus on design.

The claimed that they were generally satisfied with the help they were able to offer the project, adding that they felt most helpful in arranging connections for resources and expertise that the development team would have struggled to find on their own. They did note that the team members seemed to lack business knowledge, and when the suggestion of optional seminars and classes in these areas being offered to students was made they responded positively to the idea. 


\section{Student Enterprise Group Members}

Members of the student enterprise group felt that the single team that was formed from the AppFest event was far too big to be truly effective. Even though two team members left during the project, there simply weren't enough tasks for the large team created. This meant that too often some members were idle awaiting others to complete dependent tasks. Worse still, team members were sometimes stepping on each other's toes trying to complete tasks which could have been carried out by a single developer. Furthermore, the team was unhappy with the pay distribution. They felt there was a large disparity in work done and time spent on the project by different team members, something that was further compounded by the oversized team membership. Both the Enterprise Support Team and the Student Enterprise group members suggested that a smaller team was necessary, and that developers should be paid hourly for their attendance and work.

The group further highlighted the lack of design skills in the team; the hackathon already suffered from the same problem, which only got worse when insufficient graphic design students were pulled over into the enterprise. None of the team members interviewed felt strong in design skills and would have liked to see more design students involved in the project.

The development team expressed gratitude to the enterprise team for connecting them to resources and individuals that they would have struggled to get on their own. Academic mentors involved in the project were appreciated for the guidance provided as well as assistance for distribution to digital stores, like Google Play and the iOS app store. Mentors were very experienced and helpful with iOS, but unfortunately lacked expertise in Android development. The group was forced to seek out external support when developing the application for Android. They stated that they needed more time for testing before release. Then, following the release of the application, the team felt the application wasn't well advertised towards open day applicants; many didn't know about the app until after they had arrived on campus, which is too late to get the full benefit of using the App.

\section{Team Dynamics}

Many of the students involved in the Hackathon had been exposed to several theories of team roles and team dynamics, via the lecture programme for a second year Group Project module. In the student evaluation of this module, many students report their dislike of working in groups where they do not initially know the other group members and may also have very little knowledge of the strengths and weaknesses of other group members' skills.

In our undergraduate teaching about groups, students complete a Belbin Self Perception Inventory (SPI) and are also introduced to Tuckman and Jensen's classic model of the stages of group development (forming, storming, norming, performing and adjourning) [27]. However, data from the student interviews conducted after the Hackathon and the formation of the student company, suggest that it is groups of friends or (at least) like-minded keen individuals who elect to attend Hackathon events. Groups often form from, for example, two close friends sitting close to another small group of friends at the event and deciding to work together on the task. In this example, the students would already have a reasonable idea of the skills and competences of most of their fellow group members and, in their social interactions prior to the event, may have already been through the first four stages of Tuckman and Jensen's model. The theory therefore predicts that such a group is already quite advanced on their route to becoming a high performing team.

\section{Entrepreneurial Mindset}

Attendance and active participation at a Hackathon event is entirely voluntary and, in that sense, above and beyond the academic attendance required of an undergraduate student. In addition to this, hackathon events typically take place at the weekend where they compete in a student's schedule with other social activities. Students who choose to attend hackathon events would seem, therefore, to be part of a self-selecting group who share traits that include:

- a willingness to put in extra work, and

- possession of what might be termed a certain degree of 'get up and go' that is present to a greater degree than that of the rest of their cohort. 
The observed traits described in the two bullet points above have parallels in the work of Haynie et al [28] in their situated metacognitive model of the entrepreneurial mindset. It therefore seems likely that in selecting a group of students willing to attend a 48-hour Hackathon event run over the course of a weekend we are also, perhaps unwittingly, selecting a group of students who exhibit entrepreneurial skills in a student company and, by extension, likely to be successful in entrepreneurial activity.

\section{Employability Benefits}

As researchers who interact with these students on a weekly basis, there is a danger of confirmation bias in attempting to draw conclusions from interview data. To allay this suspicion in part it is interesting to note the 'student journey' of one participant who attended the Hackathon during his final year at university. When interviewed recently, the student was in full time employment in a graduate position with IBM. He recounted his first interview at the IBM assessment centre as part of the recruitment process:

"They didn't seem at all interested in me telling them about the modules I had studied as part of my degree. As soon as I told them about the Hackathon and the student app development company that formed after the Hackathon, that was all they were interested in. I had a similar experience in my interviews with Intel and Capital One and all three resulted in job offers."

\section{Multidisciplinary Hackathons}

The Hackathon described in this paper did attract student participation, albeit very small numbers, from Design students and also those studying in the Business School. However, these students were observed to remain grouped by discipline and there was very little interaction between them and the majority of students from the School of Computer Science.

The gender balance of the participants matched the balance evidenced in the programme cohorts. The preponderance of students with a computer science background, compounded by the lack of students from the design disciplines meant that the overwhelming majority of participants in the project were male. This is clearly out of line with the experience reported in Rae et al [29] where participation by males and females was almost equal. This is a serious concern for the design of any future hackathon activity.

One Games Computing student suggested a better way of involving non-computer science students which he had experienced at a Game Jam. Whilst he was part of a group with other Games focussed students, he was also aware that there were students from a sound engineering and recording programme present. These students introduced themselves and suggested that, when the stage was reached where audio could be added to enhance the game, they would act on a consultancy basis to help games groups add relevant audio to their games. This idea seems well worth trialling at future events where, rather than forcing cross-disciplinary students to work with coders throughout, it might be possible to have them as part of a 'helpdesk' where their skillsets could be called upon on an 'as required' basis.

\section{EVALUATION FRAMEWORK}

Pulling together the results of the interviews carried out, the authors propose the following evaluation framework:

- the student enterprise group should not have more people involved than absolutely necessary;

- the issue of payment for team members on the project should be considered well in advance;

- the use of a hackathon might lead to a heavily male to female participant gender balance unless they are selected in way that challenges the typical engagement such events;

- a hybrid model of group management for the hackathon, with managed groups of designers and developers at the outset, enhanced subsequently by students of specialist disciplines such as business and marketing, who are introduced in the latter stages, could produce a more robust and enduring team to extend into the enterprise phase;

- additional guidance in key business concepts, possibly though in-filling onto existing provision, is valued. 


\section{CONCLUSION}

Student Enterprises can be constructed in a variety of ways. Using a Hackathon to initiate a student enterprise has the benefit of bringing together a number of students from a range of backgrounds to start an enterprise together and to make the essential bonds that will help the team to stay together through the challenges that lie ahead. It is naïve to think that this alone will bring about success. The creation of key management posts to provide a structure for the company is necessary particularly to ensure sustainability and bring about growth. Fundamental issues like the team size and the reward structure need to be considered and put into place. However, as a device to locate team members with a wide range of complementary skills and to initiate a good team environment and spirit, it is certainly worthy of consideration.

\section{ACKNOWLEDGEMENTS}

The research carried out and the resulting paper were conducted under the institution's "Student as Producer" initiative where all students, including undergraduates, are encouraged to engage with the principles and practice of research. The authors would like to thank the institution for providing the funding which has enabled this activity to come to fruition.

\section{REFERENCES}

[1] D. Cobham, C. Gowen, K. Jacques, J. Laurel, S. Ringham, "From appfest to entrepreneurs: using a hackathon event to seed a university student-led enterprise", Proceedings of 11th annual International Technology, Education and Development Conference, 2017.

[2] N. Duval-Couetil, A. Shartrand, T. Reed, "The role of entrepreneurship program models and experiential activities on engineering student outcomes". Advances In Engineering Education, 5(1) 127, 2016.

[3] E. Rasmussen, P. Benneworth, M. Gulbrandsen, "How academic entrepreneurship meets the university: university spin-offs in stakeholder network". Available from http://doc.utwente.nl/97965/1/chepswpseries201511.pdf [accessed 16 May 2017]

[4] M.M. Mars, S. Slaughter, G. Rhoades, "The state-sponsored student entrepreneur", The Journal of Higher Education, 79(6) 638-670, 2008.

[5] J.M. Veciana, M. Aponte, D. Urbano, "University students' attitudes towards entrepreneurship: a two countries comparison", International Entrepreneurship and Management Journal, 1(2) 165-182, 2005.

[6] C. Bruyat, P. Julien, "Defining the field of research in entrepreneurship". Journal of Business Venturing, 16(2) 165-180, 2001.

[7] J. Marchand, A. Hermens, S .Sood, "Student entrepreneurship: a research agenda". International Journal of Organisation Innovation, 8(2) 266-281, 2015.

[8] R. Hisrich, J. Langan-Fox, S. Grant, "Entrepreneurship research and practice: a call to action for psychology", American Psychologist, 62(6) 575-589, 2007.

[9] B. Hynes, Y. Costin, N. Birdthistle, "Practice-based learning in entrepreneurship education". Higher Education, Skills and Work-based Learning, 1(1) 16-28, 2010.

[10] N. Duval-Couetil, C.M. Gotch, S. Yi, "The characteristics and motivations of contemporary entrepreneur students", The Journal of Education for Business, 89(8) 441-449, 2014.

[11] R. Henderson, M. Robertson, "Who wants to be an entrepreneur? Young adult attitudes to entrepreneurship as a career", Career Development International, 5(6) 279-287, 2000.

[12] M. Mustapha, M. Selvaraju, "Personal attributes, family influences, entrepreneurial education and entrepreneurship inclination among university students". Kajian Malaysia, 33(1) 155-172, 2015.

[13] J.M. Veciana, M. Aponte, D. Urbano, "University students' attitudes towards entrepreneurship: a two countries comparison". International Entrepreneurship and Management Journal, 1(2) 165-182, 2005.

[14] L. Kolvereid, "Prediction of employment status choice intentions". Entrepreneurship Theory and Practice, 21(1) 47-57, 1996. 
[15] H. van Auken, F.L. Fry, P. Stephens. "The influence of role models on entrepreneurial intentions". Journal of Developmental Entrepreneurship, 11(2) 157-167, 2006.

[16] N.F. Krueger, M.D. Reilly, A.L. Carsrud, "Competing models of entrepreneurial intentions". Journal of Business Venturing, 15(5-6) 411-432, 2000.

[17] M. Giannetti, A .Simonov, "Social interactions and entrepreneurial activity". Journal of Economics and Management Strategy, 18(3) 665-709, 2009.

[18] N. Bosma, J. Hessels, V. Schutjens, M. van Praag, I Verheul, "Entrepreneurship and role models". Journal of Economic Psychology, 33(2), 410-424 2012.

[19] M.N. Dehli, "Hackathons as ground for creating start-ups: evidence from THE Port 2014". Available from https://cds.cern.ch/record/2156936 [accessed 16 May 2017]

[20] C. Giardino, X. Wang, P. Abrahamsson, "Why Early-Stage Software Startups Fail: A Behavioral Framework". In: C Lassenius, K Smolander (eds) "Software Business. Towards Continuous Value Delivery". ICSOB 2014. Lecture Notes in Business Information Processing, vol 182. Springer, Cham, 2014.

[21] D. Politis, J. Winborg, A.L. Dahlstrand, "Exploring the resource logic of student entrepreneurs." International Small Business Journal, 30(6) 659-683, 2012.

[22] J. Hertel, "Real-world learning through student enterprise - the startup phase". In: 32nd Annual Frontiers in Education, Boston, MA, 6-9 November. Piscataway, NJ: IEEE (2002).

[23] J. Powell, "A review of student enterprise and entrepreneurship at Lancaster University", Available from

http://eprints.lancs.ac.uk/76449/1/A Review of Student Enterprise and Entrepreneurship at Lanca ster University Jon Powell IEEP Submission 23.07.12.pd f [accessed 16 May 2017].

[24] Burniston et al. in M. Shattock, "Making Policy In British Higher Education 1945-2011", 233-234, Open University Press, 2012

[25] G.B. Willis, "Cognitive interviewing: a tool for improving questionnaire design". Thousand Oaks, Calif: Sage Publications, 2004

[26] R.A. Wienclaw, "Interviews", Sample Survey Design -- Research Starters Business;4/1/2017 (Online Edition).

[27] B.W. Tuckman, M.A. Jensen, "Stages in small group development revisited". Group and Organisation Studies 2; 419-427, 1977.

[28] J.M. Haynie, D. Shepherd, E. Mosakowski, P. C. Earley, "A situated metacognitive model of the entrepreneurial mindset", Journal of Business Venturing 25, 217-229, 2010

[29] D. Rae, L. Martin, V. Antcliff, P. Hannon, "Enterprise and entrepreneurship in English higher education: 2010 and beyond". Journal of Small Business and Enterprise Development, 19(3) 380-401, 2012. 